\title{
Time Trend Analysis of Hypertension Prevalence, Awareness, Treatment and Control in Italy: Novel Insights from Recent National Surveys in the General Population
}

\author{
Giuliano Tocci $^{1,2}$ (D) $\cdot$ Vivianne Presta $^{1}$
}

Received: 15 April 2017/Accepted: 21 April 2017/Published online: 28 April 2017

(C) Springer International Publishing Switzerland 2017

Essential hypertension is the most common risk factor in the general population and it is has been related to a markedly higher risk of having major cardiovascular events, including myocardial infarction, stroke, congestive heart failure and cardiovascular death, in the following 10 years compared to normotension [1]. On the other hand, it has been demonstrated that lowering high blood pressure (BP) levels to less than $140 / 90 \mathrm{mmHg}$ is paralleled by a substantial reduction of cardiovascular risk, improved cardiovascular prognosis and event-free survival [2]. Hypertension, in fact, is deeply involved in the pathogenesis of atherosclerotic diseases, promoting development and progression asymptomatic structural and functional remodelling of heart and vessels towards acute cardiovascular events or death [3]. For these reasons, and in view of the large prevalence of high BP in the general population [4], preventive strategies aimed at controlling non-communicable diseases, particularly hypertension, represent a fundamental aspect of health care policies at both national and world levels. Indeed, the World Health Organization (WHO) recommended a $25 \%$ relative reduction of the prevalence of hypertension among the public health targets to be achieved within 2020 in order to reduce the global burden of diseases [5].

Systematic and periodic assessments of hypertension prevalence, awareness, treatment and control are available

Giuliano Tocci

giuliano.tocci@uniroma1.it

1 Hypertension Unit, Division of Cardiology, Department of Clinical and Molecular Medicine, Faculty of Medicine and Psychology, University of Rome Sapienza, Sant'Andrea Hospital, Via di Grottarossa 1035-39, 00189 Rome, Italy

2 IRCCS Neuromed, Pozzilli, IS, Italy in various countries around the world [6-9]. These reports have been used not only for epidemiological purposes, but mostly for planning educational and therapeutic interventions aimed at ameliorating the $\mathrm{BP}$ control rates and reducing the incidence of hypertension-related cardiovascular diseases at various levels or settings. Over the last few years, such analyses were made available also in Italy, thus confirming a high prevalence of hypertension in the general adult population, with relatively low rates of awareness and control [10-14]. Among these surveys, the analysis provided by the National Institute of Health represents the first and most inclusive assessment of hypertension prevalence and control in the general population in our Country [13, 14].

In this issue of high blood pressure and cardiovascular prevention, Di Lonardo and colleagues [15] reported an updated analysis of this large database, which included data from three large epidemiological surveys: the risk factors and life expectancy (RIFLE) study [16], the Osservatorio Epidemiologico Cardiovascolare (OEC) [17] and the Osservatorio Epidemiologico Cardiovascolare/Health Examination Surveys (OEC/HES) [18]. What is relevant from this analysis is the very long observational period, which covered three main intervals (which covered 1978-1987, 1998-2002 and 2008-2012 periods, respectively), as well as the large population sample (which included about 70,000, 9712 and 9111 adult individuals, respectively). Although participants included in these surveys may not represent the whole Italian population, as properly acknowledged by the authors, the main findings of this analysis offered some interesting aspects to be discussed on hypertension status in the general adult population in Italy.

As shown in Fig. 1, hypertension prevalence had a substantial decrease, whereas awareness and control 


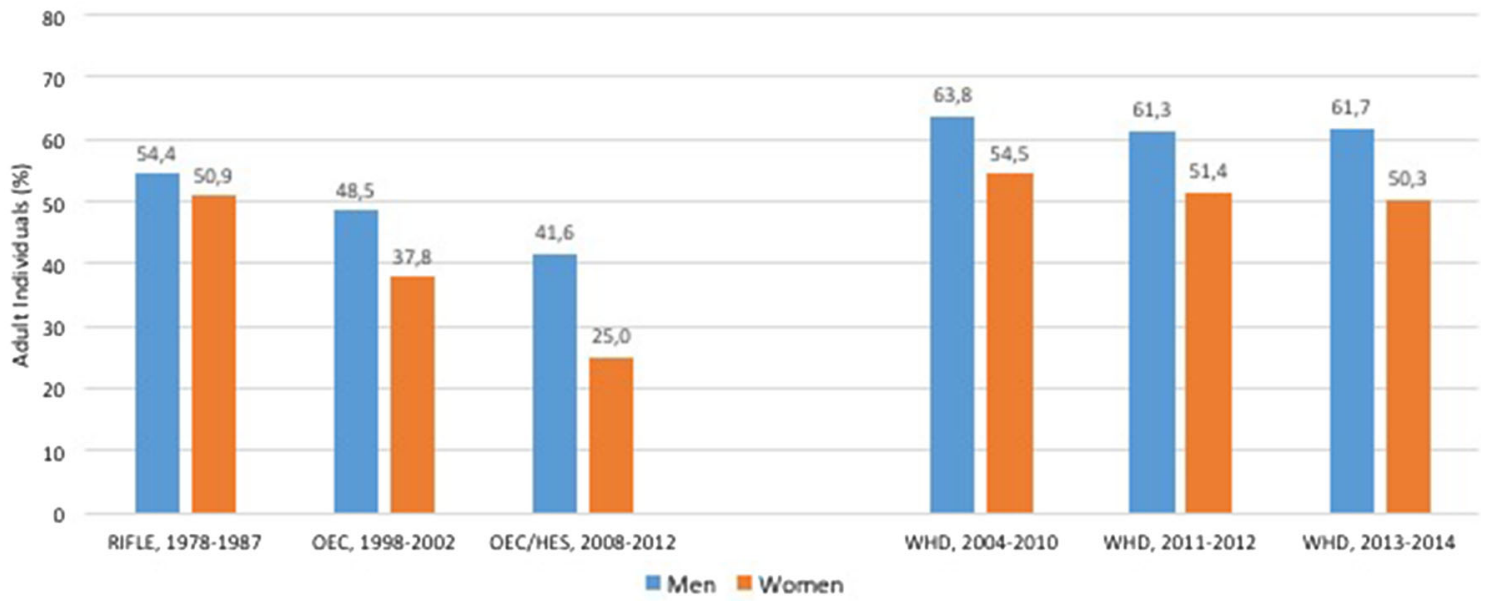

Fig. 1 Prevalence of hypertension according to gender groups in the following population surveys: risk factors and life expectancy (RIFLE) study [16]; Osservatorio Epidemiologico Cardiovascolare (OEC) [17]; the Osservatorio Epidemiologico Cardiovascolare/Health

showed a slight, but progressive increase over the three subsequent surveys in both gender groups. These findings were consistent with those from a recent population survey, which collected data from the World Hypertension Day in Italy over a relatively long observational period [10]. In this analysis hypertension prevalence decreased from about $64 \%$ to about $61 \%$ in males and from about $54 \%$ to about $50 \%$ in females [10], thus suggesting that prevention of the disease in large proportions of individuals from the general population can be achieved, although is still far from be obtained.

Another relevant aspect of the analysis is the fact BP levels were higher in male than in female individuals and that systolic BP levels were, on average, in the high-normal range (between 130 and $139 \mathrm{mmHg}$ ), whereas diastolic $\mathrm{BP}$ levels were more frequently in the normal range $(80-85 \mathrm{mmHg}$ ), independently by regions. This distribution was also consistent with another analysis performed in adult outpatients followed by general practitioners and distributed across the whole national territory [11], and indirectly confirmed that systolic BP levels are more difficult to control than diastolic BP levels.

Although with some discrepancies and with the wellknown limitations of the observational retrospective approach, the results of these surveys demonstrated that hypertension prevalence is reduced, but persistently elevated in the general adult population. This has obvious relevant consequences from both clinical and socio-economic point of views, since unaware asymptomatic individuals with high $\mathrm{BP}$ as well as treated uncontrolled hypertensive patients are at high risk of developing major cardiovascular consequences and hospitalizations due to cardiovascular diseases. For these reasons, periodic and
Examination Surveys (OEC/HES) [18]; World Hypertension Day (WHD) 2004-2014 [10]. Hypertension was defined as systolic equal or greater than $140 \mathrm{mmHg}$ or diastolic blood pressure equal or greater than $90 \mathrm{mmHg}$

thorough assessment of BP levels in the general population or in specific subgroups of high risk patients (e.g. elderly, hypertensive patients with metabolic abnormalities, diabetes, coronary artery disease or previous stroke) should be promoted at both national and regional levels, since they provide useful information that can be used for planning interventions aimed at improving hypertension management and control in Italy.

\section{Compliance with Ethical Standards}

Funding None.

Conflict of interest Authors have no conflict of interest to disclose with the contents of the present manuscript.

Ethical approval This article does not contain any studies with human participants.

\section{References}

1. Lewington S, Clarke R, Qizilbash N, Peto R, Collins R. Agespecific relevance of usual blood pressure to vascular mortality: a meta-analysis of individual data for one million adults in 61 prospective studies. Lancet. 2002;360(9349):1903-13.

2. Ettehad D, Emdin CA, Kiran A, Anderson SG, Callender T, Emberson $\mathrm{J}$, et al. Blood pressure lowering for prevention of cardiovascular disease and death: a systematic review and metaanalysis. Lancet. 2016;387(10022):957-67.

3. Volpe M, Camm J, Coca A, Unger T. The cardiovascular continuum refined: a hypothesis. Blood Press. 2010;19(5):273-7.

4. Danaei G, Finucane MM, Lin JK, Singh GM, Paciorek CJ, Cowan MJ, et al. National, regional, and global trends in systolic blood pressure since 1980: systematic analysis of health examination surveys and epidemiological studies with 786 countryyears and 5.4 million participants. Lancet. 2011;377(9765):568-77. 
5. Diem G, Brownson RC, Grabauskas V, Shatchkute A, Stachenko S. Prevention and control of noncommunicable diseases through evidence-based public health: implementing the NCD 2020 action plan. Glob Health Promot. 2016;23(3):5-13.

6. Wu L, He Y, Jiang B, Sun D, Wang J, Liu M, et al. Trends in prevalence, awareness, treatment and control of hypertension during 2001-2010 in an urban elderly population of China. PloS One. 2015;10(8):e0132814.

7. de Burgos-Lunar C, Jimenez-Garcia R, Salinero-Fort MA, Gomez-Campelo P, Gil A, Abanades-Herranz JC, et al. Trends in hypertension prevalence, awareness, treatment and control in an adult type 2 diabetes Spanish population between 2003 and 2009. PloS One. 2014;9(1):e86713.

8. Bromfield SG, Bowling CB, Tanner RM, Peralta CA, Odden MC, Oparil S, et al. Trends in hypertension prevalence, awareness, treatment, and control among US adults 80 years and older, 1988-2010. J Clin Hypertens (Greenwich). 2014;16(4):270-6.

9. Cutler JA, Sorlie PD, Wolz M, Thom T, Fields LE, Roccella EJ. Trends in hypertension prevalence, awareness, treatment, and control rates in United States adults between 1988-1994 and 1999-2004. Hypertension. 2008;52(5):818-27.

10. Tocci G, Muiesan ML, Parati G, Agabiti Rosei E, Ferri C, Virdis $\mathrm{A}$, et al. Trends in prevalence, awareness, treatment, and control of blood pressure recorded from 2004 to 2014 during World Hypertension Day in Italy. J Clin Hypertens (Greenwich). 2016;18(6):551-6.

11. Tocci G, Nati G, Cricelli C, Parretti D, Lapi F, Ferrucci A, et al. Prevalence and control of hypertension in the general practice in Italy: updated analysis of a large database. J Hum Hypertens. 2017;31(4):258-62.
12. Tocci G, Nati G, Cricelli C, Parretti D, Lapi F, Ferrucci A, et al. Prevalence and control of hypertension in different macro-areas in italy: analysis of a large database by the general practice. High Blood Press Cardiovasc Prev. 2016;23(4):387-93.

13. Giampaoli S, Palmieri L, Donfrancesco C, Lo Noce C, Pilotto L, Vanuzzo D, et al. Cardiovascular health in Italy. Ten-year surveillance of cardiovascular diseases and risk factors: Osservatorio Epidemiologico Cardiovascolare/Health Examination Survey 1998-2012. Eur J Prev Cardiol. 2015;22(2 Suppl):9-37.

14. Giampaoli S, Vanuzzo D. Cardiovascular risk factors in Italy: an interpretation with reference to th National Health Plan 1998-2000. Research Group of the Cardiovascular Epidemiologic Observatory. Giornale italiano di cardiologia. 1999;29(12):1463-71.

15. Di Lonardo A, Donfrancesco C, Palmieri L, Vanuzzo D, Giampaoli S. Time trends of high blood pressure prevalence, awareness and control in the Italian general population. High Blood Press Cardiovasc Prev. 2017. doi:10.1007/s40292-017-0201-8.

16. The RIFLE Research Group. Presentation of the rifle project risk factors and life expectancy. Eur J Epidemiol. 1993;9(5):459-76.

17. Menotti A, Seccareccia F, Lanti M, Farchi G, Conti S, Dima F, et al. Mean levels and distributions of some cardiovascular risk factors in Italy in the 1970's and the 1980's. The Italian RIFLE Pooling Project. Risk factors and life expectancy. Giornale italiano di cardiologia. 1995;25(12):1539-72.

18. Kuulasmaa K, Tolonen H, Koponen P, Kilpelainen K, Avdicova M, Broda G, et al. An overview of the European health examination survey pilot joint action. Arch Public Health. 2012;70(1):20. 